\title{
Co-opetition Strategy in Volunteer Computing: The Example of Collaboration Online in BOINC.RU Community
}

\author{
Victor Tishchenko \\ Division “Community Informatics”, Federal Research Center `Computer Science and Control`of Russian Academy of Sciences, \\ Russia
}

Copyright $\mathrm{C} 2018$ by authors, all rights reserved. Authors agree that this article remains permanently open access under the terms of the Creative Commons Attribution License 4.0 International License

\begin{abstract}
Volunteer computing (VC) is a strong way to harness distributed computing resources to perform large-scale scientific tasks. Its success directly depends on the number of participants, PC (some other devices) and time of their work. And while the computational aspect received much effective research attention and solutions; the social problem of VC phenomenon - how persuade the owners of widely dispersed smart machines and devices to participate in VC projects, and how figure out ways to speed and expand the capability of donated computer resources, remains largely unexplored. We think that a motive of self-actualization of participants of volunteer computing is not enough to explain why millions of unskilled people day by day participate in scientific computation. Our research indicates that the answer lies at the intersection of self-oriented motivation and the interactional, organizational possibilities emerging through the Internet. In this paper we investigate Russian community of VC and discuss the suggestion that online collaboration can capture people's motivation better than only intrinsic motives.
\end{abstract}

Keywords Co-opetition, Volunteer Computing, Online Collaboration, Virtual Communities

\section{Introduction}

The complexity of the tasks facing modern science is accompanied by the complexity of the computations. For solving computational problems, along with supercomputers distributed computing is used nowadays. Technically distributed computing is performed by a number of different processors, which reside in one device (multiprocessor computer) or on different machines. In the last sense computers may be on the same network (the case of clusters), or on networks that are physically located far away from each other. So, in this paper the distributed computing term will be used to glean knowledge that will deepen our understanding of an emerging type of computer-mediated online communication, which carried out scientific computing.

\subsection{Concept of volunteer computing}

One of the forms of the distributed computing is the volunteer computing (VC), a specific form of online activity of volunteers, ordinary Internet users, who have no any relation to scientific or professional computer activities, and who do not receive compensation for their participation. So, we use the notion of volunteer computing as a type of a distributed computing in which unskilled computer owners can donate their spare computer resources to perform a computation of one or more large-scale research projects. Unlike peer-to-peer (P2P) or grid computing, $\mathrm{VC}$ relies on the client-server architecture. (Figure 1).

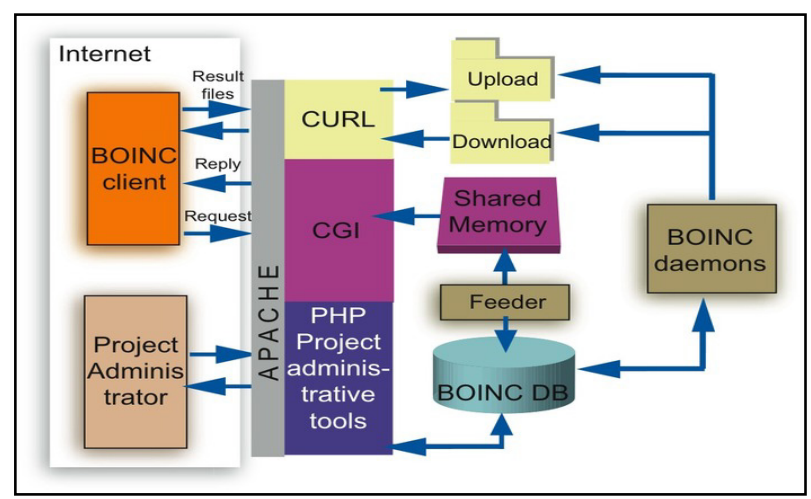

Figure 1. Scheme of BOINC platform (VC-participation)

As a result, volunteers` desktops, notebooks, mobile phones can be virtually connected to form through Internet a network equivalent to a huge and superpower supercomputer. As a high-performance distributed 
computing platform, BOINC brings together about 4,5 millions (157,814 active) participants and more than 1,2 millions (778,490 active) computers (hosts) worldwide processing on average 20.996 PetaFLOPS, as of 31 July 2018 [1].

The concept of VC is based on the ideas of the network organization of communications and the emergence of the paradigm of the network society as a whole $[2,3]$. The principal technical background of $\mathrm{VC}$ is the idea of David Gedye [4], one of the founder of the project SETI@home ("Search for Extraterrestrial Intelligence"), to use dispersed desktops for computing large-scale scientific tasks [5], the software decision to integrate a lot of personal computers of Internet users in a virtual network on a special platform. In 2002, at the University of California, Berkeley the BOINC (The Berkeley Open Infrastructure for Network Computing), an open-source middleware system was designed; an open-source platform dedicated to running volunteer computing projects [6].

As for VC-projects, typically academic-based research assignments, they are based on 3 pillars (Figure 2).

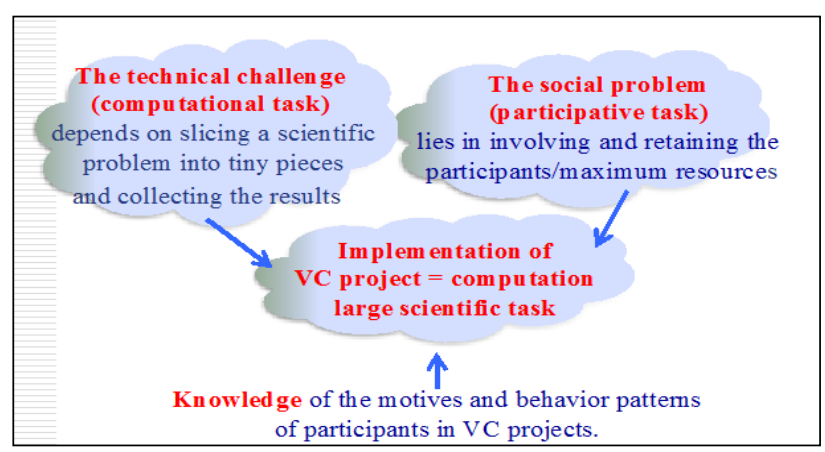

Figure 2. Basic principles of VC-project organization

- $\quad$ Technical task (computational): slicing a problem into thousands of tiny pieces which are then allocated (with a help of downloading project software) to a large number of individuals who volunteer their PC (notebooks, etc.) to scientific computing;

- $\quad$ Social task (participation): recruiting and retaining a large number of individuals to volunteer their computer resources, time and energy to the project, and facilitating their continuous contribution;

- Knowledge task (motives knowing): understanding of motifs to speed and expand the capability of volunteer computer resources to use for performance computing.

And while the computational aspect of $\mathrm{VC}$ received much research attention, the participative and knowledge aspects remain largely unexplored. In order to understand the phenomenon of VC we have to look "inside" it. And we find two spaces.

At first, it is a computational VC-space. As it was mentioned earlier, $\mathrm{VC}$ relies on the standard client-server architecture where clients (software programs) "talk" only to the project server and do not talk to one another directly. So, in order to participate in a VC project, a user must download the project software from the VC project website and install it on their computer. Once installed, the project software contacts the project website and is assigned a task. Upon solving the task, the result is sent back to the project server and a new task is downloaded if the user so desires. Look at the arrows in Figure 1.

The implementation of $\mathrm{VC}$ project depends on the number of connected ("included") computers, their resources and time of their work. So, project managers/organizers used a special conditional points accrual mechanism to encourage participation in VC-projects. The project's server keeps track of how much work your computer has done; the number of accrued points (crédits) depends on the provided capacities, the time of participation in a project and other characteristics of the activity of volunteers or their teams. To ensure that crédits are granted fairly, most BOINC projects work as follows:

Each task may be sent to two computers;

When a computer reports a result, it claims a certain amount of credit, based on how much CPU time was used;

When at least two results have been returned, the server compares them. If the results agree, then users are granted the smaller of the claimed crédits.

As for social underpinning of VC-projects, we should note a non-traditional form of VC social structure. Emerging from individual participation at the first stages of $\mathrm{VC}$, nowadays VC-volunteers, instead of traditional scientific research conducted inside a hierarchical institution, form a specific kind of a virtual scientific community which working towards the common goal of scientific research. The whole multitude of VC-participants is not a "sack" of volunteers. Participants in $\mathrm{VC}$ projects can either work alone or join a team and work together on the same project. A team typically consists of a group of people with a common nationality (country), thematic or institutional (same university, place of work, etc.) affiliation. As a whole there are 107,503 teams that united more than 4,5 million participants in the VC projects [7]. Mainly VC-teams have their own websites dedicated to the projects; they also host online user groups in social media. So all these online discussion services allow the volunteers cooperate by sharing knowledge and expertise and progress the team and individual team members.

And all VC-projects have their own websites that are used to host the project software, disseminate information about performing the project, and a ranking table of volunteers' activity. On websites there are also online discussion forums where the volunteers can discuss different aspects and technical problems of distributed computing of a project, attempt to resolve any technical 
problems that may arise during the running of the projects.

So, we can say that VC is a dispersed network of teams and individuals, projects' and team sites, online forums and online user groups. As VC projects are by their nature decentralized, the volunteer's virtual communication through online forums, team home pages, and VC-project websites form a communal virtual place.

So, the VC-community organizational framework consists of:

- projects - typically academic-based research assignments, e.g. search for "Extra-Terrestrial Intelligence", understand of protein folding and related diseases, learn global warming, discover pulsars; there are 51 most active projects, (http://www.boincstats.com);

- individuals - Internet-connected low-powered computers $=$ average person or organization (volunteers), not paid for their work, anonymous, working alone (just about $16,9 \%$, survey May, 2018);

- VC teams - a long-term strategic alliance formed by volunteers, individual users of $\mathrm{PC}$, in order to participate in solving large scientific computational task (just about $83,1 \%$, survey in May, 2018);

- Internet resources - e.g., project websites with statistics in rank tables, discussion forums, etc.

\subsection{Motivations for participation in VC-projects}

Research on motivation for involvement in collaborative $\mathrm{VC}$ scientific projects goes back to the studies analyzing the factors shaping and developing the digital "civil science" [8]. These studies show that "categories of civil science", in other words, the factors that determine the distribution of participants in voluntary computing, depend on the nature and objectives of the projects. And the whole multitude of volunteers is located in the interval, beginning with the "technical" tasks, in which their participation is reduced only to the provision of computer resources for computations (such as the SETI@home project or the Folding@home project of computer modeling of protein molecule folding) and ending with more complex problems, for the solution of which both collection and analysis of distributed data are required (Stardust@home projects on classification of interstellar dust particles or Galaxy Zoo, project of construction of visual images/images of galaxies). In total, according to researchers, it is possible to describe three types of projects and, accordingly, three "strats" of the participants.

The revealed differences in the distribution of volunteers underscore the need for a detailed study of the motives for participating in such projects. And, first of all, in VC-projects, entry into which does not require participants to do anything other than downloading the BOINC platform and embedded ("connecting") computers into a network of distributed resources. Obviously, the implementation of such projects directly depends on the motivations of volunteers to participate in the project, and, accordingly, on the number of "connected" personal computers and on the time of their provision for use in the project. However, the researchers and organizers of $\mathrm{VC}$ projects do not have an unambiguous answer to the question: how can a significant scientific project requiring large-scale calculations form an environment that will stimulate the contribution of resources by many volunteers?

According to the researchers of the BOINC community [9-12] the main motivations of $\mathrm{VC}$ participants for participating in the projects are:

- Sense of involvement in important scientific research, co-ownership;

- Sense of social interaction, identification with the community, the need for communication with people close to hobbies;

- Sense of struggle, competition, the demand for awareness of social status in the form of assessments of social activity.

At the same time, as noted in the literature, in general, the totality of motives for involving Internet users in VC-projects and for "connecting" computers to a network of distributed resources, as well as preventing the release of volunteers from projects, still requires its solution [13].

So, the main question of the project managers remains unanswered: Why do volunteers decided to participate in VC-projects?

Most sociological studies of the motivations of volunteers' behavior were based on the representation of the VC-community as a set of participants in VC-projects and as a result, the research focuses only on the motivation of individual participants.

But we think that a motive of self-actualization of participants of volunteer computing is not enough to explain why millions of common people regular (day by day) participate in scientific computation. Our research indicates that the answer lies at the intersection of self-oriented motivation and the interactional and organizational possibilities emerging through the Internet. We suggest: online collaboration can capture people's motivation better than only intrinsic motives. And the questions to be answered are:

- Is there any collaboration in volunteer computing?

- Does this collaboration affect a performance computing?

The basis of the conclusions about the motivations of the VC-participants, mentioned earlier, is the result of sociological surveys of the participants of VC-projects. And naturally they are characterized by a high degree of 
arbitrariness or subjectivity (albeit involuntary) in the evaluation of volunteers' reasons and motivations of their participation in VC-projects. In this connection, it is important to develop a methodology for verifying the totality of the motives of VC participants based on formalized methods for analyzing their behavior.

The use of clustering methods for the analysis the behavior of the participants in the BOINC.RU community showed that the motives of volunteers to donate their time, financial and technological resources VC-projects, still remain largely uncovered [14]. As a possible factor that determines the behavior and activity in the selection of projects by volunteers, the collaborative interaction that is inherent in participants in virtual communities is considered.

\section{Aims, Objectives and Methodology}

So, it is obviously that the implementation of VC-project directly depends on the number of participants, PC (other machines) and time of their work, and so we will show that along the project managers, VC-community figures out collaboration ways to speed up and expand the capability of their computer resources for computing scientific tasks. So the focus of our research is the activity of the volunteers that is measured in points (crédits) and indicated how much time and computer resources have been donated for computing in the project.

As a metric of the activity of volunteers (measuring the amount of computational time and resources/efforts donated by each volunteer/team) we used a number of crédits that are charged by project managers to the team or individuals. Statistics of crédits are taken from rating tables posted on the statistical website of BOINC (www.boincstats.com) or websites of VC-projects.

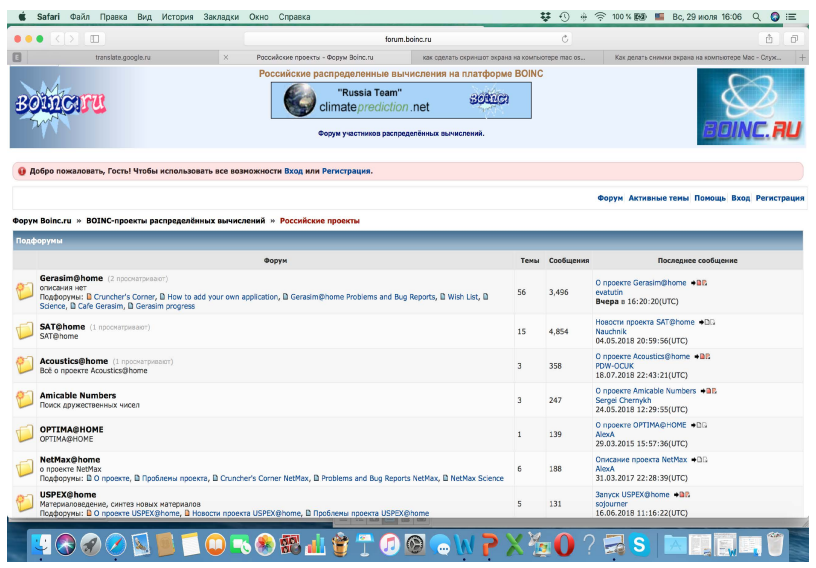

Figure 3. Screenshot of the list of Russian projects

In the study we investigate the Russian VC-community at the soft platform BOINC; (www.boinc.ru). In Russia community there 58,047 volunteers, which are united in 823 teams, as of 31 July 2018. Currently, as a whole, there are 51 active research $\mathrm{VC}$-projects using the BOINC platform, and of a total active VC-projects there are 11 projects that were designed by researchers from Russian research centers (Figure 3). The aims of Russian BOINC projects are to solve mathematical problems, tasks of underwater acoustics, materials sciences, computer-based testing methods for drug development, protein structure modeling, etc. (http://forum.boinc.ru/default.aspx?g=topic $\mathrm{s} \& \mathrm{f}=108$ ).

To conduct a statistical and clustering analysis of the behavior of Russian participants in the $\mathrm{VC}$, we used the data obtained with the websites www.boincstatistic.com and www.boinc.ru. (Figure 4), that includes statistical characteristics of the activity of both individual volunteers and their teams. The information is obtained using the API BOINC. The script for getting data was written in PHP, for data storage MySQL database was used.

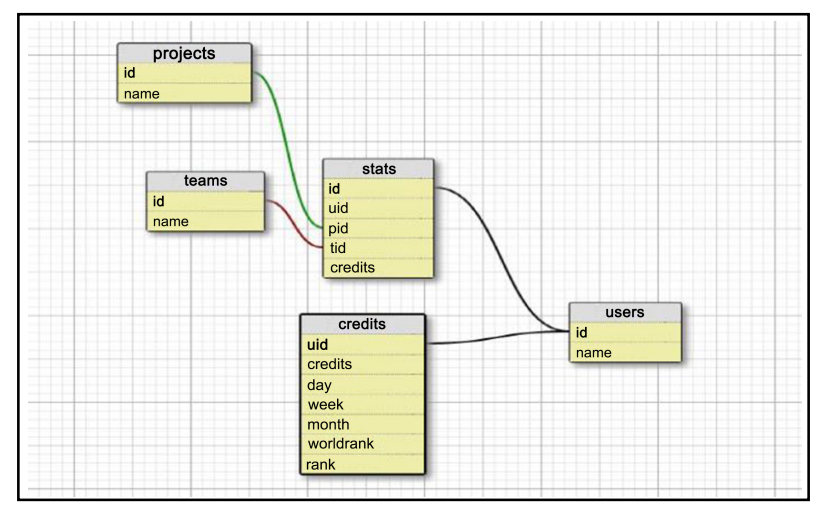

Figure 4. The structure of database "Community BOINC.RU

The database contains unique participant identifiers, participant names, unique project identifiers, project names, number of units (crédits) of participants/teams for the last week, month, year and all the time, participants' ownership of projects, unique team IDs, team names, team memberships.

Networks of Boinc.ru community were visualized with a help of algorithms "Gephi" and "Force Atlas 2".

\section{Statistical Characteristics of the Virtual Community BOINC.RU}

Since our previous study in 2014 [15] we have the opportunity to compare the results and dynamics of user activity. In comparison with 2013 there is a decrease in the activity of participants in the Russian virtual community BOINC.RU in VC-projects.

According to the 'country' rating, Russia moved from 11 places (in 2014) to 51 - in 2018. A similar decrease was noted in the share of "Russian" points (crédits); from $2.5 \%$ in 2014 to $0.4 \%$ in 2018 . And this is while the indicators of the overall activity of all volunteers increased in 17 times. The decrease in the activity of the 
BOINC.RU community participation is observed with the increase in the total number of Russian volunteers from 45 333 in 2014 to 58044 in 2018 (July 31), as well as the number of projects in which they participate from 135 in 2014 to 178 in 2018 [16].

Significant changes in the statistical characteristics of the activities of Russian participants in BOINC projects, in our opinion, are caused by the "stratification" of the community of volunteers into strata of 'active' and 'passive' participants. In 2018, the group of the most active volunteers (about 200 participants), gaining more than 100 billion points, increased 2.5 times. While the rest of the volunteers (almost all 58 thousand) collectively collect no more than 20 million points.

In the middle of 2018 (July, 31) greater than 4 $574^{`} 000$ participants in BOINC-projects from 252 countries are united in 107503 teams. Russian participants of the BOINC-project registered more than 58'000 united in 823 teams (Figure 5).

\begin{tabular}{|c|c|c|c|c|c|c|c|c|c|c|}
\hline 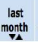 & $\begin{array}{l}\text { last } \\
\text { week }\end{array}$ & $\begin{array}{l}\text { last } \\
\text { daly }\end{array}$ & Team Name & $\begin{array}{l}\text { Total } \\
\text { coefilit } \\
\text { the }\end{array}$ & $\begin{array}{l}\text { Creditt } \\
\text { /dady }\end{array}$ & $\begin{array}{l}\text { Crededt } \\
\text { /week }\end{array}$ & $\begin{array}{l}\text { Credit } \\
\text { Imonth }\end{array}$ & Average credit & $\begin{array}{l}\text { Oover } \\
\text { take }\end{array}$ & $\begin{array}{l}\text { Options } \\
\text { Compre } \\
\end{array}$ \\
\hline of & of & ot & 1 Russia & $29,393,944,997$ & $18,651,072$ & 105,939769 & $455,550,999$ & $: 6,360,214$ & & LLith \\
\hline o* & o* & ot & 2 Russia Team & 15,881,014,397? & $10,280,378$ & 72,999,683 & $283,590,574$ & $9,902,827$ & & LLtith \\
\hline ow & of & ot & 3 onsk & $9,823,119,725$ & $20,055,917$ & $105,332.656$ & $462,802,453$ & $15,959,625$ & $565+$ & LLtith \\
\hline of & of & ot & $4 \mathrm{TSC}$. Russia & $7,548,890,511$ & $2,456,679$ & $16,396,430$ & $64,928,598$ & $2,291,493$ & . & L情 \\
\hline ot & of & ot & 5 Cystol Dream & $7,288,682,352$ & 7173997 & $10,015,1,160$ & $42,289,132$ & $1,542,399$ & & 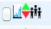 \\
\hline ot & ot & ot & 6 DCRussin Union & $3,114,222,124$ & $12,534,007$ & $65,119,522$ & $278,154,132$ & $9,519,162$ & $2365+$ & Lजith \\
\hline or & ot & ot & 7 Astoromyngu form & $2,318,249,301$ & $1,029,375$ & $11,940,351$ & 72,42, 1,591 & $1,993,58$ & & LUtith \\
\hline ot & ot & ot & B Boncre Russin & $1,971,681,642$ & 520,391 & $5,396,872$ & $28,02,1,375$ & 803,579 & 9 & Lutith \\
\hline on & ot & ot & 9 s.r.etersburg & $1,916,191,047$ & 238,046 & $1,655,938$ & $9,18,137$ & 26,180 & $\cdot$ & LLitit \\
\hline 1t & ot & o* & 10 Sakhalin fussia & $1,800,8757,704$ & 41,242,046 & $191,420,242$ & $70,472,699$ & $27,321,402$ & 5 & ЈL部 \\
\hline 14 & ot & o+ & 11 ketherisksou & $1,180,670,781$ & 455,708 & $4,531,967$ & 19,143,704 & 682,314 & 4 & LLith \\
\hline or & ot & ot & 12 PlabserI & $939,027,567$ & 356,793 & $1,936,599$ & 4,512,262 & 182,798 & & L情 \\
\hline or & of & ot & 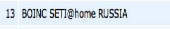 & $755,893,159$ & 195,071 & $1,376,926$ & $5,868,082$ & 183908 & 8 & L㟄 \\
\hline on & o* & ${ }_{0 *}^{*}$ & 14 keegni & $750,152,119$ & 1,911,51 & $13,102,097$ & $52,338,8: 4$ & $1,822,767$ & 77 23 & LUtith \\
\hline ow & o* & o* & $15 \mathrm{MEPH}$ & $531,742,316$ & 8,001 & 45,331 & 20,936 & 8,738 & 38 & LLtith \\
\hline ow & of & ot & 16 RJ-Fam & $369,521,619$ & 43,232 & 272,986 & $1,244,237$ & 40,556 & $66365+$ & 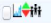 \\
\hline ot & ot & ${ }^{0+}$ & 17 vgtt & $327,563,557$ & 0 & 0 & 0 & 1 & 1 & Lजि \\
\hline ot & ot & ot & 18 A AB 3004 & $266,843,369$ & 154,057 & 840,102 & $1,933,6993$ & 94,127 & $27365+$ & Lज़ी \\
\hline
\end{tabular}

Figure 5. Screenshot of the list of Russian teams

\section{Collaborative Network`s Effect}

As it was mentioned above, participation in $\mathrm{VC}$ is voluntary and participants do not receive compensation for their work. So project managers/organizers in search of a mechanism to encourage participation in VC-projects use conditional points accrual mechanism. The number of these points («credits») depends on the provided capacities, the time of participation in projects, and other characteristics of the activity of volunteers and their teams. The availability of constant statistics for all projects, in addition to tracking various ratings, provokes various virtual competitions ("challenges") between participants and teams. And many of the projects create an environment for the competitors by volume computations are done, both individually and in the team event. Thus modus operandi of $\mathrm{VC}-$ is spirit of competition. If volunteers are members of a team, they are simultaneously competing with the other teams on the project on the more immediate goal of racking up the most contributions and coming out on the top of the table of statistics documenting contributions.

This form of cooperation and competition individually and in combination (in teams) demonstrates a new type of online scientific collaborative network - co-opetition. This term was proposed by Brandenburger A. M. and Nalebuff B. J. [17] in 1996 year to describe a new phenomenon of cooperative competition of firms. Co-opetition is a kind of interaction of firms when companies interact with partial congruence of interests. As Dagnino G. and Padula Giovanna noted [18], they cooperate with each other to reach a higher value creation if compared to the value created without interaction and struggle to achieve competitive advantage. Often co-opetition takes place when companies that are in the same market work together in the exploration of knowledge and research of new products. Holohan A. and Garg A. [11] used this term metaphorically in their paper to describe a collaboration of volunteers in VC-projects to affect a performance of computing. To prove the possibility of describing the collaboration of volunteers using this term, Holohan A., Garg A. relied a number of theoretical concepts and the results of their sociological surveys. However, they do not describe either the process of co-competition in VC-projects and neither its results that enhances the computing.

I think that nowadays we can use this term not only in a metaphorical or theoretical sense, but also as an actual mechanism for managing volunteer computing.

As an example, we can cite the Russian project SAT@home [18], which is actively supported by national volunteers. The active group of volunteers organizes competitions ("challenges") between several teams from different countries. As a result of these competitions the performance of the SAT@home project was increased (Figure 6). For the period of each of these competitions the project's productivity increased by about 7,4 teraflops with the average value in 4,3 teraflops.

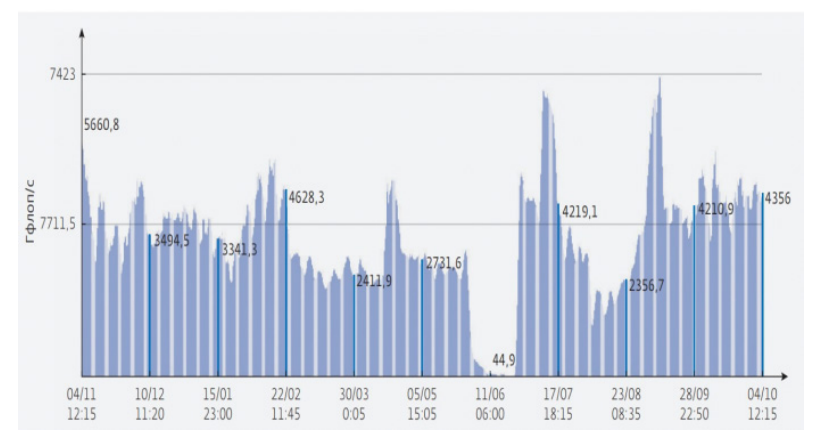

Figure 6. The performance of the SAT@home project. The peaks correspond to the moments of the competition among teams of volunteers.

In order to highlight traces of collaborative networks we will allocate links between the active volunteers in a whole Boinc.ru community. The background of looking for the active participants is based on the idea that only a 
few participants of virtual communities are the most effective in obtaining the most important results. For example, in the study of the OSS projects was showed that only a small subset is significant, $85-90 \% \%$ of the code was written by about 15 developers [20].

For determining an active group of participants in VC-projects in Boinc.ru community we have used the accrued credits, assumed that a person took part in the project if he collected at least 50,000 points in it. So it appeared - 200 volunteers, who participated in 2176 projects. To visualize and analyze links (simultaneous participation of two volunteers in a project) between volunteers we use the Gephi software and the Force Atlas 2 algorithm.

Having constructed a connectivity table, where aij - the number of general projects for two volunteers, we construct a graph (Figure 7).

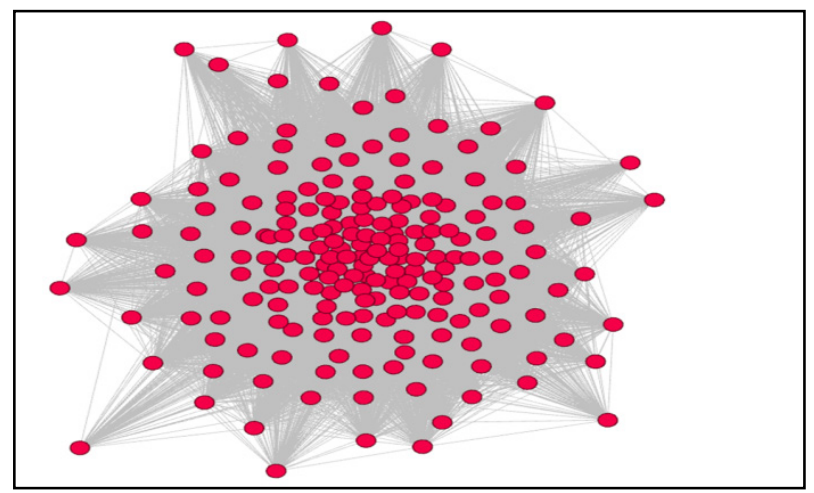

Figure 7. Visualization of links in active volunteers`group $(>50000$ credits, 2176 projects)

Increasing the participation threshold in the project to 100000 crédits, followed by up to one million crédits hardly changes the picture evaluation of the participation of the 200 most active volunteers. The screenshot of the diagram of a participation in 1217 projects (Figure 8).

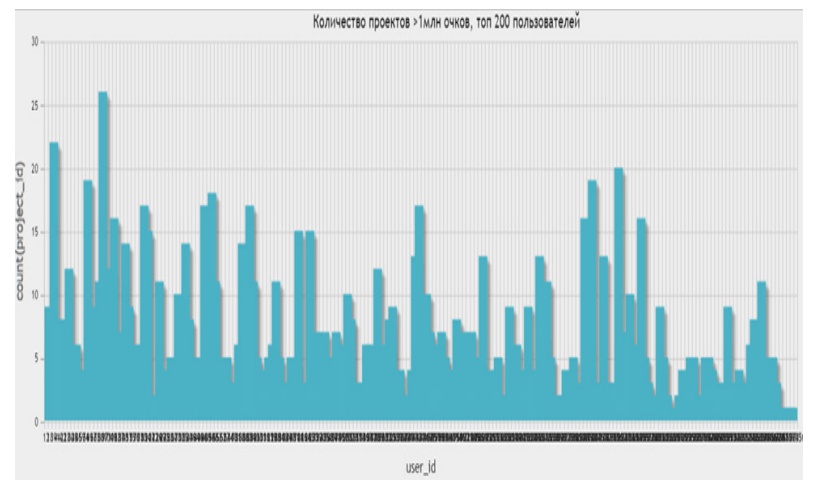

Figure 8. Number of projects for 200 participants with greater than $1,000,000$ points

For this case we construct a similar graph. The picture has not changed at all (Figure 9).

The density of the new graph is 0.774 . Thus, we can conclude that either there are projects (and we recall, excluded from the links one project SETI@ HOME because more than 24,000 volunteers participate in it) in which all users participate, or we need to increase the threshold of participation in the project again.

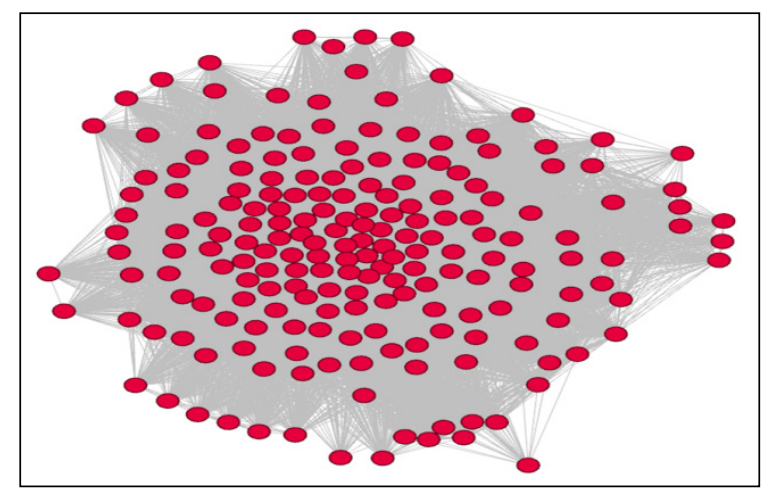

Figure 9. Visualization of links in active volunteers ' group $(>1,000,000$ credits greater than 1 million)

In spite increasing the threshold the form of graphs does not change. It means that almost all active users are connected with some projects.

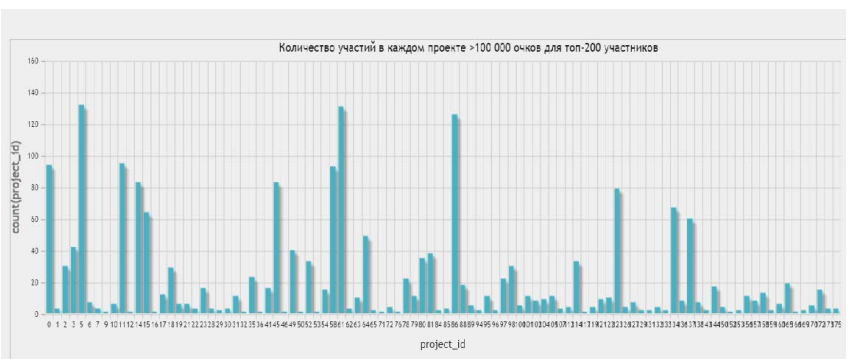

Figure 10a. Distribution of 200 active participants in the projects (> 100,000. points)

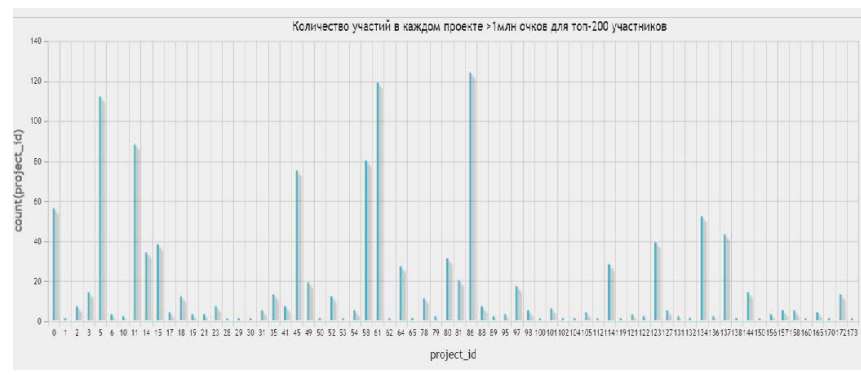

Figure 10b. Distribution of 200 active participants in the projects ( $>$ $100,000,000$ points)

Furthermore in spite increasing the threshold the distribution of the participants in the projects are very similar (Figures 10a\&10b). And as can be seen from the distribution and height of the peaks, which corresponds to the number of participants in the projects, these active volunteers participate in almost the same projects. The most active users are not inclined to participate in projects "on trial", they thoroughly approach the choice of the project and actively participate in the accruals.

Let's see the connections between users in Russian 
projects. From all of them there are 9 on BOINC platform: Gerasim@home, SAT@home, Acoustics@home, Amicable Numbers, Stop@home, OPTIMA@HOME, ODLK@home, AndersonAttack, XANSONSforCOD.

Consider participation in the project with a score of more than 500 (this is due to the fact that many projects launched in 2016-2017). It turned out 2,300 participations for 1800 people - in our opinion, this is a rather modest indicator and we do not have to talk about any serious intersections. It's clear that they will be in the main between the old projects Gerasim@home and SAT@home; 1528 and 557, according to the order of projects.

If we consider the remaining projects, with the exception of the two mentioned earlier - we will get 230 links for 150 people. Since the links here are much less than when studying the active users for all projects, the picture is also more expressive.

If we look for the communication between participants of all Russian projects, and construct a connectivity graph of participants in Russian projects (Figure 11), we see the graph of the links (participation) of volunteers in 7 projects.

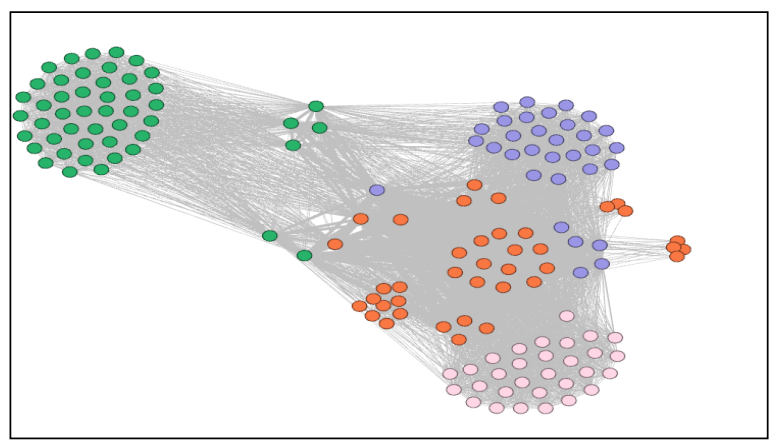

Figure 11. Collaborative network; orange cluster is dedicated to the collaborative community

All volunteers were divided into two large groups (shown in color in the figure 11).

Let's see the statistics of participation in projects in each of the groups (clusters) identified on the graph.

Table 1. Number of participations in projects

\begin{tabular}{|c|c|c|c|c|}
\hline Projects & Cl. green & Cl. violet & Cl. orange & Cl. rose \\
\hline $\begin{array}{c}\text { Acoustics } \\
\text { @ home }\end{array}$ & 4 & 32 & 18 & \\
\hline $\begin{array}{c}\text { Amicable } \\
\text { Numbers }\end{array}$ & 2 & 6 & 19 & 27 \\
\hline $\begin{array}{c}\text { Anderson } \\
\text { Attack }\end{array}$ & 19 & 1 & 10 & 1 \\
\hline $\begin{array}{c}\text { Xansons } \\
\text { for Cod }\end{array}$ & 1 & 1 & 3 & \\
\hline $\begin{array}{c}\text { Optima@ } \\
\text { Home }\end{array}$ & 49 & 30 & \\
\hline $\begin{array}{c}\text { Stop@Ho } \\
\text { me }\end{array}$ & 1 & 6 & \\
\hline Odlk & & & \\
\hline
\end{tabular}

Considering the participation rates of volunteers in new Russian projects, we can argue that the preferences and actions are fairly coherent. We managed to single out a group of volunteers, which actively participates in several projects (cluster "orange" on the graph). Cluster "orange" is formed at the 'intersection` of clusters "green" and "violet + rose + orange", respectively.

The unification of volunteers into the orange group, without a provocation, shows that these are not only active, but also interested community members who follow the BOINC space, analyze the information and agree on the preference for new projects. Such behavior of the community members testifies, very likely, about their interaction with each other on third-party network resources.

Considering the participation of users in the new Russian projects, we can assert that their actions are sufficiently consistent: we obtained a connected graph, the density of the graph is 0.47 . In addition, we managed to identify a group of users who are actively participating in the main of projects (this is the "orange" group of users in the graph, Figure 11), which certainly indicates either that these are active interested users who receive information about new projects, monitor for the BOINC system and, very likely, interact with each other on third-party resources.

\section{Features of Team Behavior in BOINC.RU Community}

It remains to consider the behavior of participants in the system within the team and check the consistency of the election of projects. The team «Russia Team» was chosen as the research object. In the team, there are 2300 participants with more than 1000 points. The diagram below shows the 20 most popular projects for this team (Figure 12).

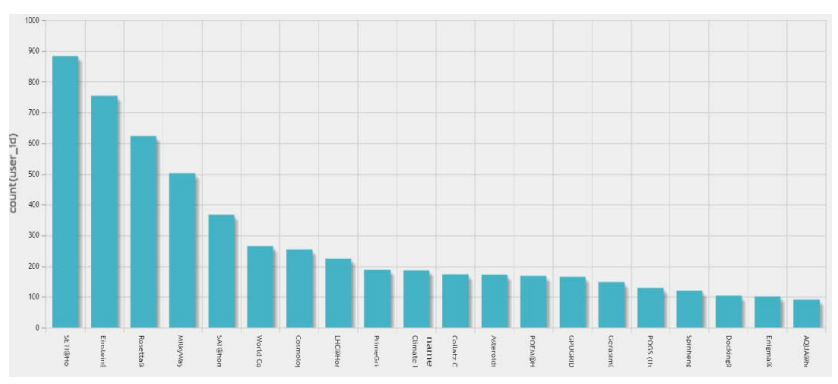

Figure 12. The distribution diagram for the projects of the participants of the team "Russia Team"

Considering the data, we can conclude that an important factor after or before joining the team is the joint selection of projects in which to participate (Table 2). This is an important conclusion, which indicates the importance of teams in the BOINC project, that the desire to carry out concerted activities for the sake of achieving scientific results and team victories is an important factor for the participants. This is especially noticeable if we consider the 1000 active users from the team (they have more than 100,000 points) (Table 3 ). 
Table 2. Statistical characteristics of the participation of the team "Russia Team" in popular projects

\begin{tabular}{|c|c|c|}
\hline Project & $\begin{array}{l}\text { Number of } \\
\text { participants }\end{array}$ & Points (crédits) \\
\hline SETI@Home & 883 & 615553359 \\
\hline Einstein@Home & 754 & 2246881460 \\
\hline Rosetta@Home & 623 & 136362985 \\
\hline MilkyWay@home & 502 & 2845666113 \\
\hline SAT@home & 367 & 196251721 \\
\hline World Community Grid & 265 & 230090485 \\
\hline Cosmology@Home & 254 & 88145128 \\
\hline LHC@Home & 224 & 26469540 \\
\hline PrimeGrid & 188 & 3395986927 \\
\hline Climate Prediction & 186 & 31529434 \\
\hline Collatz Conjecture & 173 & 3699396223 \\
\hline Asteroids@home & 172 & 250128360 \\
\hline POEM@HOME & 168 & 1254617928 \\
\hline GPUGRID & 165 & 2649208233 \\
\hline Gerasim@Home & 148 & 88944208 \\
\hline POGS (theSkyNet) & 129 & 123237755 \\
\hline Spinhenge@home & 120 & 19967832 \\
\hline Docking@Home & 104 & 45473601 \\
\hline Enigma@Home & 101 & 15943350 \\
\hline
\end{tabular}

Table 3. Statistical characteristics of the participation of members (which have more than 100,000 points) the team "Russia Team" in popular projects

\begin{tabular}{|c|c|c|}
\hline Project & $\begin{array}{c}\text { Number of } \\
\text { participants }\end{array}$ & Points (credits) \\
\hline SETI@Home & 478 & 609888006 \\
\hline Einstein@Home & 475 & 2241762103 \\
\hline MilkyWay@home & 371 & 2843496091 \\
\hline Rosetta@Home & 365 & 132399871 \\
\hline SAT@home & 286 & 195074054 \\
\hline LHC@Home & 206 & 26201734 \\
\hline World Community Grid & 196 & 228536560 \\
\hline Cosmology@Home & 185 & 87325330 \\
\hline PrimeGrid & 161 & 3395384130 \\
\hline POEM@HOME & 155 & 1254326403 \\
\hline Collatz Conjecture & 151 & 3698634058 \\
\hline GPUGRID & 151 & 2648743627 \\
\hline Gerasim@Home & 136 & 88758612 \\
\hline Asteroids@home & 132 & 249394560 \\
\hline Climate Prediction & 129 & 30896870 \\
\hline POGS (theSkyNet) & 117 & 123045433 \\
\hline
\end{tabular}

The number of participants in the projects has changed not significantly, and where the number has changed practically did not affect the number of points. You can note: active users in the team participate in more projects

Their actions and the choice of projects are coordinated this choice is the results of communications in the team, or joining the team - the result of the team's participation in these projects users with a small number of points prefer to choose just the most popular projects

The density of the graph for the team Russia Team for 1000 active users is 0.65 . In general, the results are similar to the graph that we considered for the 1000 most active users; only in the team version the users have much fewer points and projects in which they participate. This, again, indicates that the actions inside the team are fairly coordinated and users, presumably, seek to monitor the information within the team.

\section{Conclusions}

The data obtained as a result of statistical analysis of the behavioral characteristics of the participants in the virtual community BOINC.RU, show that the participation of users in Russian projects and their actions are sufficiently coordinated. Nowadays we can describe of the behavior of Russian VC-community with a help of the notion co-opetition; it is not a metaphorical or theoretical sense, but a real and actual mechanism for managing volunteer computing.

We have obtained a connected graph; the density of the graph is 0.47 . In addition, we managed to identify a group of users who are actively involved in several projects. Analysis of the characteristics of the constructed graph allows us to assume that active volunteers get information on new projects and monitor the system BOINC and, very likely, interact with each other on third-party resources. All this gives grounds for presenting, at least, this segment of the BOINC.RU community as a collaborative community whose activities determine not only the behavior of these community members, but is a significant factor in the implementation of projects.

The most active and productive participants in VC exemplify co - opetition - collaboration within the network organization of a VC project.

Our research indicates that the motivation of participation of millions of unskilled volunteers in VC-projects lies at the intersection of intrinsic motivation and the organizational possibilities emerging through the collaboration. In providing the means for channeling participants' motivations to compete and cooperate, $\mathrm{VC}$-projects provide powerful insights into a new type of collaborative network.

So, VC-community model - collaborative network

\section{Acknowledgements}

We are very grateful to my colleague Alex Prochko who performed the necessary calculations for this paper. We also very grateful to Russian Foundation for Basic Research which funded this research; projects 16-29-12922 and 16-29-12940 


\section{REFERENCES}

[1] BOINC, Online available from https://boinc.berkeley.edu.

[2] M. Castells. The Information Age: Economy, Society and Culture. Volume 1: The Rise of the Network Society. Oxford: Blackwell, 1996.

[3] J. Arquilla \& D. Ronfeldt. Social Networks and Netwar. Santa Monica, CA: Rand Corporation, 2001.

[4] SETI@home Classic: In Memoriam, Online available from https://setiathome.berkeley.edu/classic.php

[5] W. T. Sullivan, III, D. Werthimer, S. Bowyer, J. Cobb, D. Gedye, D. Anderson. A new major SETI project based on Project Serendip data and 100,000 personal computers of Astronomical and Biochemical Origins and the Search for Life in the Universe, Proc. of the Fifth Intl. Conf. on Bioastronomy, IAU Colloq. No. 161, Capri, July 1-5, 1996, eds. C. B. Cosmovici, S. Bowyer, and D. Wethimer (Publisher: Edtrice Compositori, Bologna, Italy), P. 729, 1997, Online available from http://seticlassic.ssl.berkeley.e du/woody_paper.html/ (retrieved 2018-07-31)

[6] David P. Anderson. BOINC: A System for Public-Resource Computing and Storage of 5th IEE. ACM International Workshop on Grid Computing, November 8, 2004, Pittsburgh, USA, pp 1-7, 2004, Online available from http://boinc.berkeley.edu/grid_paper_04.pdf (retrieved 2018-07-31).

[7] BOINC, Detailed stats BOINC combined, Online available from https://boincstats.com/en/stats/-1/project/detail (retrie ved 2018-07-31).

[8] Nov, O., Arazy, O., and Anderson, D. (2011). Technology-Mediated Citizen Science Participation: A Motivational Model of Proceedings of the AAAI International Conference on Weblogs and Social Media (ICWSM 2011). - Barcelona, Spain, - July 2011, Online available

http://faculty.poly.edu/ onov/Nov_Arazy_Anderson_Citiz

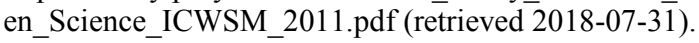

[9] [9] Andreev A. Sociologiya GRID [GRID Sociology]. Troitskiy variant, № 166, November 04, 2014. P. 8. (In Russian), 2014, Online available from http://trv-science.ru/2014/11/04/sotsiologiya-grid/ (retrieved 2018-07-31).

[10] Iakimets V. N., Kurochkin I. I. Volunteer distributed computing in Russia: sociological analysis (in Russian) of Proc. XVIII conference "Internet and modern society" (IMS-2015), Sant-Peterburg, 23-25 июня 2015 г. University ITMO, 2015, pp. 345-352, Online available from http://openbooks.ifmo.ru/ru/file/2263/2263.pdf ((retrieved 2018-07-31).

[11] Holohan A., Garg A. (2005) Collaboration Online: The
Example of Distributed Computing. Journal of Computer-Mediated Communication. 2005 - Vol. 10, issue 4. Article 16, Online available from http://onlinelibrary.wiley.com/doi/10.1111/j.1083-6101.20 05.tb00279.x/full (retrieved 2018-07-31).

[12] Oded Nov, Ofer Arazy, David Anderson. Scientists@Home: What Drives the Quantity and Quality of Online Citizen Science Participation? PLOS One, April 1 2014, Online available from

http://www.plosone.org/article/info\%3Adoi\%2F10.1371\% 2Fjournal.pone.0090375/ (retrieved 2018-07-31)

[13] Peter Darch, Annamaria Carusi Retaining volunteers in volunteer computing projects Phil. Trans. R. Soc. A (2010) 368, 4177-4192. Online available from http://rsta.royalsocietypublishing.org/ (retrieved 2018-07-3 1)

[14] Victor Tishchenko (2017) Behavioral patterns of volunteer computing communities//BOINC-FAST 2017: International Conference BOINC:FAST 2017. Proceedings of the Third International Conference BOINC-based High Performance Computing: Fundamental Research and Development (BOINC:FAST 2017) Petrozavodsk, Russia, August 28 - September 01, 2017.- P. 55-60// Online available from https://ceur-ws.org)// ISSN 1613-0073//Vol-1973 urn:nbn:de:0074-1973-0/ (retrieved 2018-07-31)

[15] Tishchenko V. I., Prochko A. L. Russian participants in BOINC-based volunteer computing projects. The activity statistics. // Computer Research and Modeling - 2015 Vol. 7 - Issue 3 - P. $727-734$ (in Russian).

[16] Tishchenko V. I., Prochko A. L. Virtual community of Russian participants of voluntary computing on the BOINC platform // Proceedings of presentations and articles of NSCF'2017, in Russian, Online availlable from http://2017.nscf.ru/prezentacii/ (retrieved 2018-07-31)

[17] Brandenburger, A. M. , \& Nalebuff, B. J. Co - Opetition: A Revolutionary Mindset That Combines Competition and Co - Operation. Garden City, N.Y.: Doubleday, 1996.

[18] Dagnino, Giovanni Battista, and Padula, Giovanna (2002). Coopetition Strategy: Towards a New Kind of Interfirm Dynamics for Value Creation, EURAM 2nd annual conference, Stockholm School of Entrepreneurship, Sweden 8-10 May.

[19] Andreev A. L. Voluntary computing in Russia through the eyes of a cruncher. Current state and development prospects of Proc. National Supercomputing Forum (NSCF-2013), Pereslavl-Zalesskiyi, 2013, November, 26-29, The Program Systems Institute of RAS from Online available https://docplayer.ru/30920179-Andreev-a-1-dobrovolnye-ra spredelennye-vychisleniya-v-rossii-glazami-kranchera-sov remennoe-sostoyanie-i-perspektivy-razvitiya.html.

[20] Weber S. The Success of Open Source. Cambridge: Harvard University Press, 2004. 